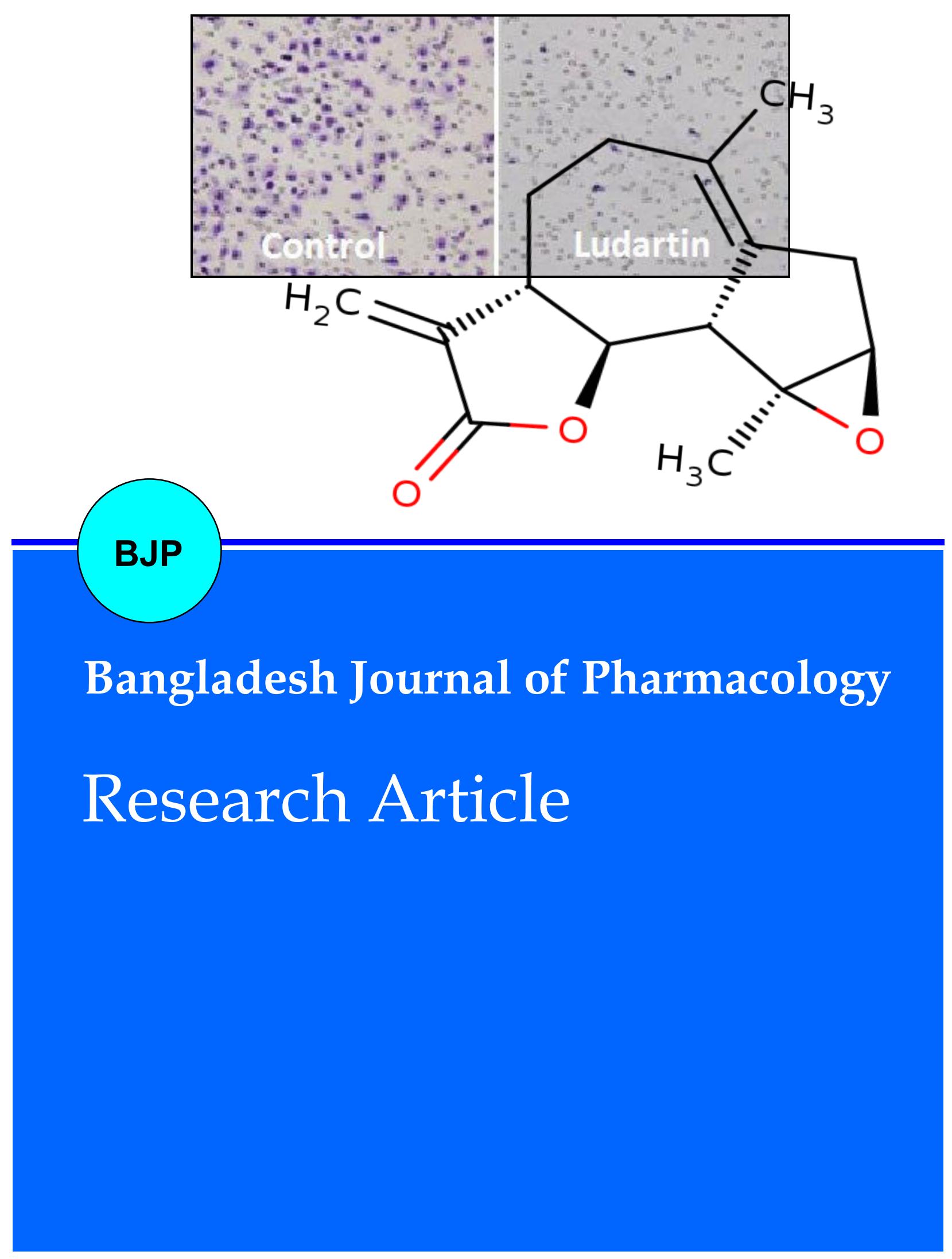




\title{
Ludartin treatment exhibits promising inhibitory effect on the epithelial ovarian cancer growth and metastasis
}

\author{
Lin Bai, Hui Wang, Luo-Ying Zhang, Ai-Hua Wang and Jie Bai
}

Department of Obstetrics and Gynecology, The First People's Hospital of Shangqiu, Henan 476-100, China.

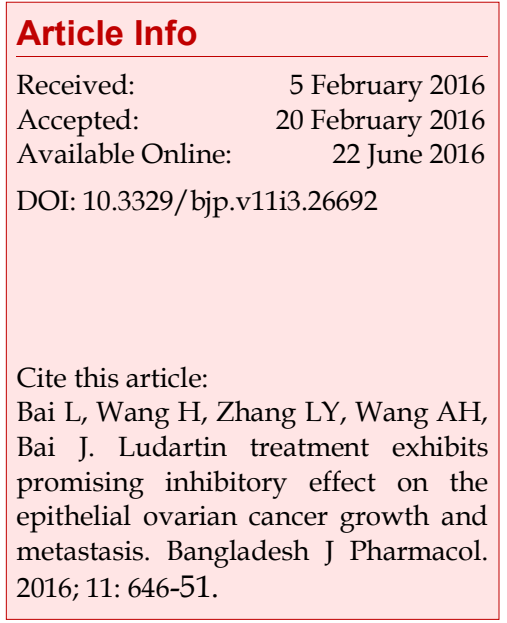

\begin{abstract}
In the present study, the effect of ludartin on OVCAR5 ovarian carcinoma cells was investigated. MTT cell assay was used for the analysis of cell viability and wound healing assay for migration potential. Results revealed that ludartin treatment at 10 and $30 \mu \mathrm{M}$ doses reduced the cell viability from 94 to $38 \%$. The invasive potential was decreased from 62 to $24 \%$ with increase in ludartin concentration from 10 to $30 \mu \mathrm{M}$. Western blot analysis showed that ludartin treatment reduced the expression of p-FAK in OVCAR5 cells significantly. Ludartin treatment for 48 hours also caused a significant decrease in the expression of MMP-2 and MMP-9 in OVCAR5 cells at a concentration of $30 \mu \mathrm{M}$. The metastatic regions were absent in the rats treated with $30 \mu \mathrm{M} / \mathrm{kg}$ doses of ludartin daily for 15 days. Thus, ludartin treatment inhibits the proliferation, invasion and migration of ovarian cancer cells through down-regulation of pFAK and MMPs, therefore can be used for the treatment of ovarian cancer.
\end{abstract}

\section{Introduction}

Ovarian carcinoma constitutes one of the commonly detected cancer of reproductive tract in females and is associated with high rate of mortality. The 5 year survival rate of the ovarian cancer bearing women is very low (<30\%) (Raki et al., 2006). Failure to detect the ovarian cancer at an early stage and dearth of effective treatment strategies hinders its treatment (BertoneJohnson, 2005). Thus, the identification of a molecule which can effectively inhibit ovarian cancer is highly desired.

Sesquiterpene lactones have been the subject of interest for researchers throughout the globe because of a broad spectrum of biological activities. Ludartin is the position isomer of arglabin isolated from Artemisinin magdalena has been reported to possess gastric cytoprotective activity (Blanco et al., 1997). It has also been reported to inhibit the activity of aromatase enzyme which plays an important role in the breast cancer (Blanco et al., 1997; Muftuoglu and Mustata,
2010). Taking into account the biological activity, the structure activity relationship studies of ludartin have also been performed with the aim to develop potential anti-cancer drug.

In the present study, the effect of ludartin on ovarian cancer cell invasion and migration was investigated. Ludartin treatment inhibited proliferation and reduced adhesion, invasion and migration potential of OVCAR5 ovarian cancer cells through inhibition of $\mathrm{pFAK}$ and MMPs expression.

\section{Materials and Methods \\ Chemicals}

Ludartin was purchased from Sigma Chemical Co. (USA). RPMI 1640 medium was supplied by Gibco BRL (USA) whereas the penicillin and streptomycin were purchased from North China Pharmaceutical Group Corp. (China). 


\section{Cell line and culture}

OVCAR5 human ovarian cancer cell line was purchased from the American Type Culture Collection (USA). The cells were cultured in Dulbecco's-modified Eagle's medium (DMEM, Gibco, USA) supplemented with 10\% fetal bovine serum (Hyclone, USA) along with penicillin (107 U/L) and streptomycin (10 mg/L). Incubation of the cells was performed at a temperature of $37^{\circ} \mathrm{C}$ in a humidified atmosphere of $5 \% \mathrm{CO}_{2}$.

\section{Animals}

Twenty female Sprague-Dawley rats (aged 3 months; weighing $\sim 200 \mathrm{~g}$ ) were obtained from the Hubei Laboratory Animal Center (China; License No. SCXKE2014-0201).

\section{Analysis of cell adhesion}

Into the 96-well matrigel (BD Biosciences, China) coated plates, OVCAR5 cancer cells at a density of $2 \times 10^{5}$ cells/well were seeded. The cells were incubated with $0,10,20$ or $30 \mu \mathrm{M}$ concentrations of ludartin for 48 hours. The cells after adherence for 1 hour to the matrigel were washed with ice-cold PBS to remove the non-adherent cells. The proportion of cells adhered to matrigel in ludartin treated plates was compared to the control cell plates.

\section{In vitro invasion assay}

Into the bottom and top layers of the Transwell chamber (pore size, $5 \mu \mathrm{M}$ ) was placed DMEM supplemented with 10\% FBS and without FBS, respectively. The density of OVCAR5 cancer cells in the suspension was maintained at $2 \times 10^{5}$ cells $/ \mathrm{mL}$. From this cell suspension, $50 \mu \mathrm{L}$ was put into the upper chamber of the Transwell chamber and incubated for 48 hours with ludartin. After incubation, the adhered cells in the

\section{Box 1: Cell proliferation assay}

\section{Principle}

Cell proliferation assay is used to measure the cell viability and proliferation using yellow colored tetrazolium MTT (3(4,5-dimethylthiazolyl-2)-2,5-diphenyltetrazolium bromide). MTT is reduced by metabolically active cells by dehydrogenase enzymes to generate reducing equivalents (NADH and $\mathrm{NADPH}$ ). The resulting intracellular purple formazan can be solubilized and quantified by spectrophotometer.

\section{Requirements}

OVCAR5 ovarian cancer cells, microtiter plate reader with filters, multi-channel pipette, incubator $\left(37^{\circ} \mathrm{C}\right)$, inverted microscope, laminar flow hood and MTT cell proliferation kit (Roche Applied Science)

\section{Procedure}

Step 1: The cells $\left(2 \times 10^{5}\right.$ cells/well $)$ were incubated with 0,10 , 20 or $30 \mu \mathrm{M}$ concentration of ludartin for $12,24,48$ or 72 hours at $37^{\circ} \mathrm{C}$. interior chamber were harvested, fixed in $10 \%$ formalin and then subjected to Giemsa staining. The proportion of the cells migrated through the membrane was calculated to determine the membrane penetration rate.

\section{Wound healing assay}

In the wound healing assay, OVCAR5 cancer cells were seeded onto 6-well plates (BD Biosciences, China) and grown to confluent monolayers. The cells were cultured for 12 hours in RPMI-1640 medium in the absence of FBS. A wound area was produced using a pipette tip through the center of the well followed by washing with serum-free RPMI 1640. Ludartin at various concentrations $(0,10,20$ or $30 \mu \mathrm{M})$ was added to each well of the plates and the plates were incubated for 48 hours. The images of the wound area were then captured digitally at three randomly selected areas.

\section{Western blotting}

OVCAR5 cancer cells were incubated with various conditions of ludartin and then lysed using cell lysis buffer (Epitomics, USA) with $1 \mathrm{mM}$ phenylmethyl sulfonyl fluoride (Sigma-Aldrich, USA) and $20 \mu \mathrm{L} / \mathrm{mL}$ protease inhibitor mix (GE Healthcare, UK). The cell lysates were subjected to centrifugation at a temperature of $4^{\circ} \mathrm{C}$ at $14,000 \times \mathrm{g}$ for $20 \mathrm{~min}$. The concentration of proteins in the supernatants was determined using bicinchoninic acid protein assay kit (Pierce, USA). Protein extracts along with $2 x$ Laemmli sample buffer were heated to $95^{\circ} \mathrm{C}$ for $3 \mathrm{~min}$ and the $20 \mu \mathrm{g}$ samples were then isolated on SDS polyacrylamide gel (Bio-Rad Laboratories, USA) by electrophoresis. The proteins were then transferred overnight onto immobilon-P polyvinylidene fluoride membrane (Millipore) blocked with 5\% non-fat dried milk in TBS-T (50 mM Tris, 150 $\mathrm{mM} \mathrm{NaCl}$ with $0.1 \%$ Tween-20). The membranes were incubated with antibodies against MMP-2 (1:1000),

Step 2: Then $10 \mu \mathrm{L}$ of MTT solution was added to each well and incubation was continued for 4 hours more.

Step 3: The media was removed and dimethyl sulfoxide (150 $\mu \mathrm{L})$ was added to each well for dissolving formazon crystals.

Step 4: The plates were placed in a shaker and then the absorbance for each plate was recorded at $490 \mathrm{~nm}$ using a microplate reader (3550-UV, Bio-Rad, USA).

The reading were taken in triplicates for each well.

Click the Video clip

Precaution

MTT is insoluble in standard culture medium. Formazan crystals produced during reduction must be dissolved in DMSO.

\section{References}

Berridge et al., 2005

Rahman and Hussain, 2015 
MMP-9 (1:500), p-FAK (1:500), $\beta$-actin (1:1000; housekeeping protein) (Cell signalling, China) and FAK (1:250) ( $\mathrm{R}$ and $\mathrm{D}, \mathrm{China}$ ) for overnight at $4^{\circ} \mathrm{C}$. After incubation, the membranes were washed with PBS followed by 1 hour incubation with horseradish peroxidase-conjugated anti-mouse IgG (GE Healthcare) diluted 1:5000 in TBS-T. The antibody-bound proteins detection was performed by enhanced chemiluminescence system (GE Healthcare).

\section{Establishment of ovarian cancer in vivo}

Female Sprague-Dawley rats were administered with 1 $x 10^{5}$ OVCAR5 cancer cells into back side of the body. The developed tumors were sliced into thin sections and implanted into the right ovary by laparotomy. Both extraction and implantation of the tumors were performed after rats were anesthetized using sodium sorbitol. After 7 days of tumor implantation, 10 rats in the treatment group were intraperitoneally injected $30 \mu \mathrm{M} /$ $\mathrm{kg}$ doses of ludartin daily for 15 days. The control group of rats were given the same volume of normal saline. The animals were sacrificed on day 16 after the start of treatment under anesthetized conditions using sodium sorbitol to extract liver, lungs, kidneys and intestine. The tissues were fixed in $10 \%$ neutralbuffered formalin and embedded in the paraffin. The paraffin embedded tissues were cut into thin sections, deparaffined in boiling xylene, stained using $\mathrm{H}$ and $\mathrm{E}$ and then analyzed for histopathological changes.

\section{Statistical analysis}

The statistical analysis was performed using SPSS software, version 17.0 (SPSS, Inc., Chicago, IL, USA). The mean \pm standard deviation was determined and data were analyzed using one-way analysis of variance. All experiments were performed at least three times. $\mathrm{p} \leq 0.05$ was considered to indicate a statistically significant difference.

\section{Results}

\section{Carcinoma cell proliferation}

Proliferation of the OVCAR5 carcinoma cells was inhibited by ludartin treatment in concentration- and timedependent manner. Increase in the concentration of ludartin from 10 to $30 \mu \mathrm{M}$ reduced the OVCAR5 cell proliferation from 94 to $38 \%$ compared to $100 \%$ in the control cell cultures (Figure 1). The inhibitory effect of ludartin on the cell proliferation was significant $(\mathrm{p}<0.05)$ at $30 \mu \mathrm{M}$ concentration of ludartin after 48 hours.

\section{Adhesive and invasive potential}

OVCAR5 cells showed a significant $(p<0.005)$ decrease in the adhesive potential on treatment with ludartin for 48 hours compared to the control cells (Figure 2A). At the concentrations of 10 and $30 \mu \mathrm{M}$, ludartin reduced invasive potential of OVCAR5 cells by 24 and $62 \%$, respectively compared to the control. The invasive potential of OVCAR5 cells was also decreased significantly $(\mathrm{p}<0.005)$ by treatment with ludartin for 48 hours (Figure $2 \mathrm{~B}$ ).

\section{Migration potential}

The results from wound healing assay showed inhibition in the migration potential of OVCAR5 cells by ludartin treatment. With the increase in concentration of ludartin from 10 to $30 \mu \mathrm{M}$, there was decrease tendency of OVCAR5 cells to penetrate the gap as recorded from 43 to $6 \%$ after 48 hours (Figure 3 ).

\section{Expression of FAK, p-FAK, MMP-2 and MMP-9}

Results from Western blot analysis showed that ludartin treatment reduced the expression of p-FAK in OVCAR5 cells significantly compared to control cells (Figure 4). Ludartin treatment for 48 hours led to a

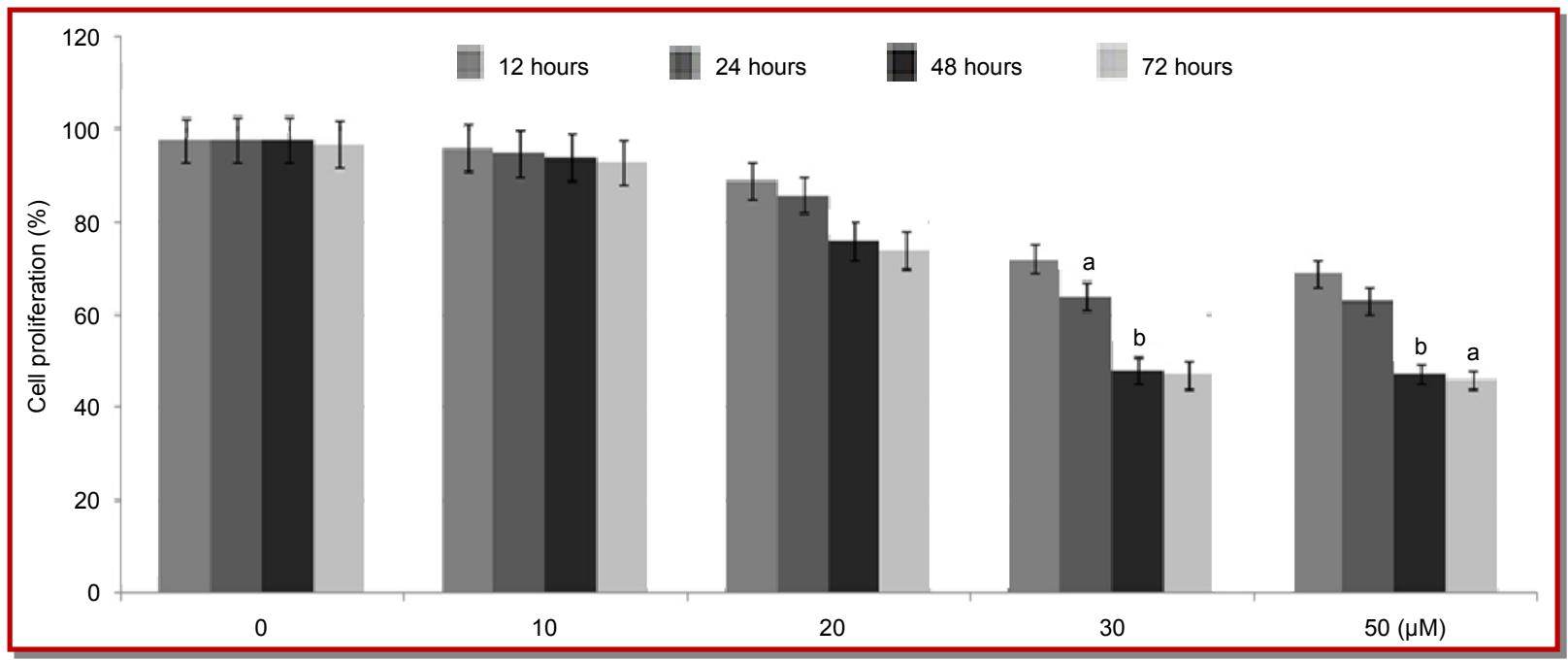

Figure 1: Reduction in the rate of proliferation in OVCAR5 cells by treatment with ludartin for 24,48 and 72 hours. The effect of ludartin on proliferation rate of OVCAR5 cells was analyzed by MTT assay. The results expressed are the mean \pm SEM. ap $<0.05$ compared with the control 


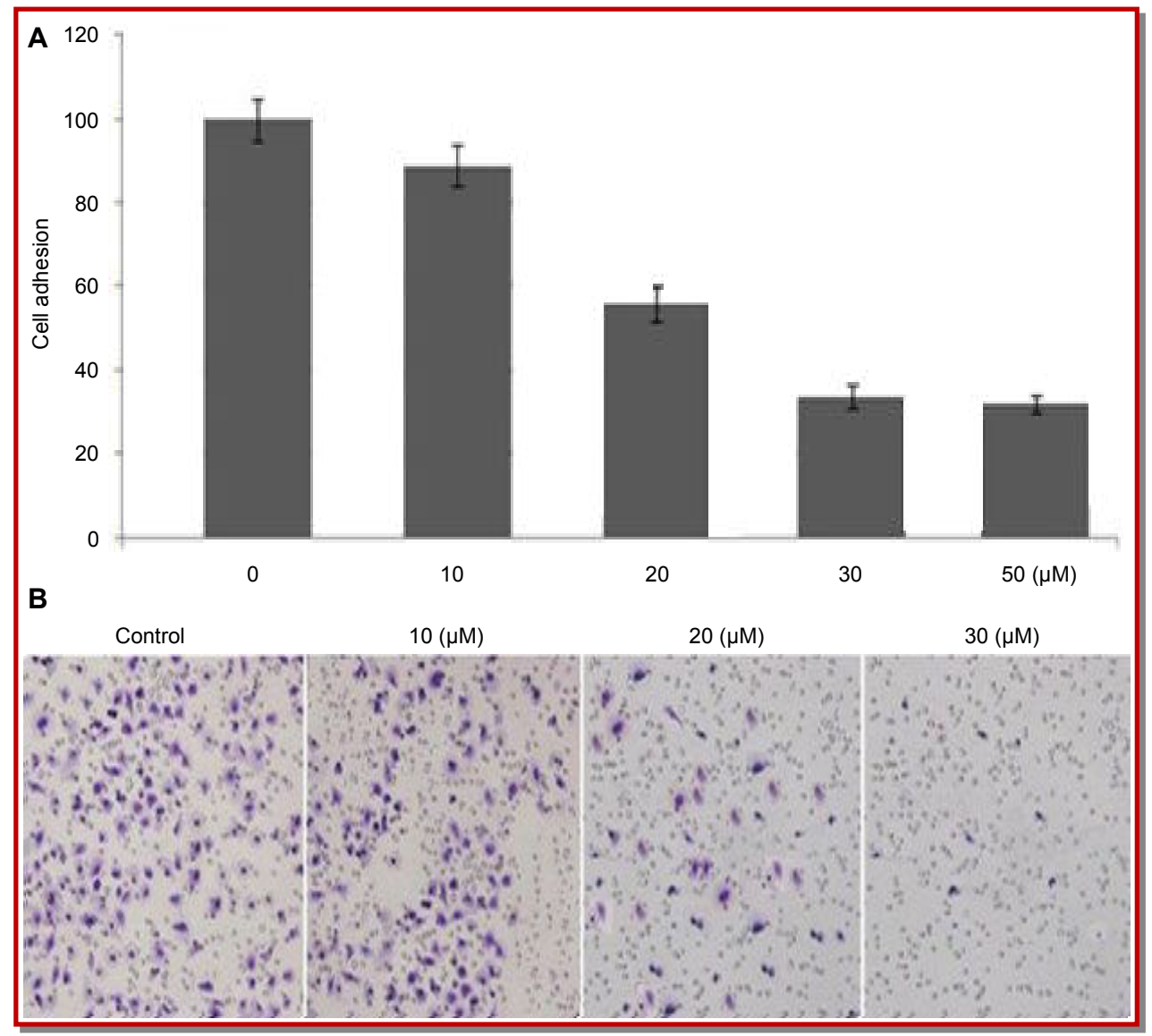

Figure 2: Effect of ludartin at various concentrations on adhesion and invasion of OVCAR5 cells. The cells after ludartin treatment were analyzed for cell adhesion and invasion. ${ }^{b} \mathrm{p}<0.05$ compared with the control cells

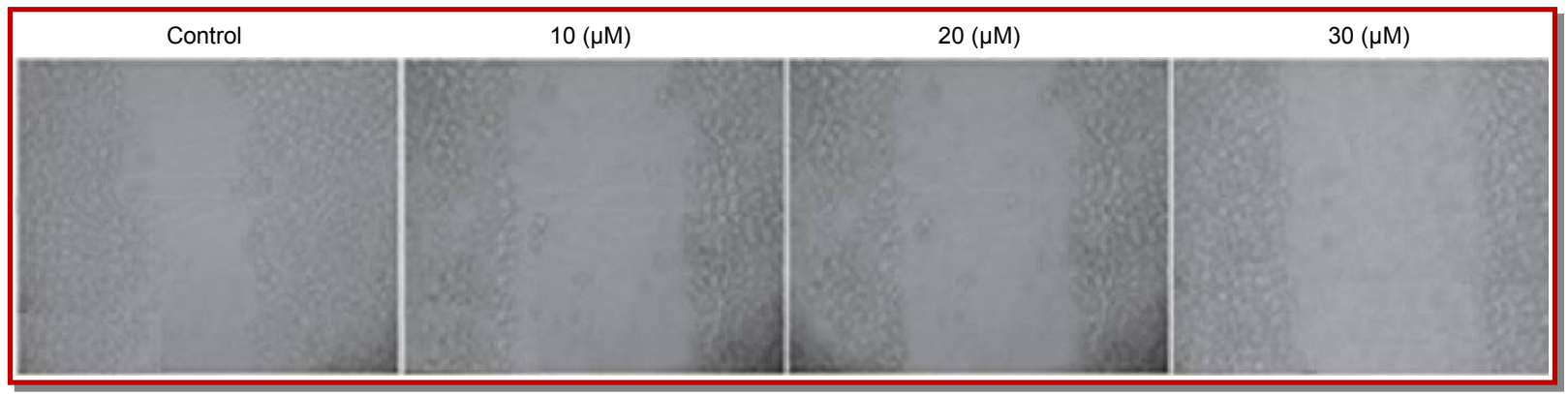

Figure 3. Effect of ludartin at various concentrations on migration potential of OVCAR5 cells. The cells after ludartin treatment were analyzed for cell migration using wound healing assay. ${ }^{b} p<0.05$ compared with the control cells

significant $(\mathrm{p}<0.005)$ decrease in the expression of MMP -2 and MMP-9 in OVCAR5 cells at a concentration of 30 $\mu \mathrm{M}$ (Figure 4).

\section{Histopathology of rats with orthotopic tumors}

The tissue sections of lungs in the control group of rats with orthotopic tumors clearly showed metastatic regions. However, the metastatic regions were absent in the rats treated with $30 \mu \mathrm{M} / \mathrm{kg}$ doses of ludartin for 15 days (Figure 5). In the control group of rats, the metastatic regions were also visible in the intestinal tissues. On the other hand, no metastatic regions were seen in the intestinal tissues of rats treated with ludartin for 15 days (Figure 5).

\section{Discussion}

The present study shows that ludartin treatment inhibited the proliferation and reduced adhesive, invasive and migration potential of ovarian cancer cells through inhibition of p-FAK and MMP-9 expression.

One of the characteristic feature of aggressive tumors is that following separation the cells adhere to the 


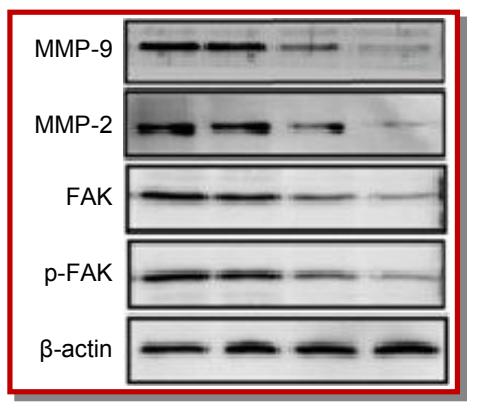

Figure 4: Inhibition of FAK, pFAK, MMP-2 and MMP-9 expression in OVCAR5 cells by ludartin treatment. The cells after incubation with ludartin or DMSO (control) were subjected to western blot analysis using $\beta$-actin as internal control

receptors present in cell membranes which facilitates the cell migration and invasion (Zhang and Wang, 2006; Cattaruzza and Perris, 2005). There are reports that inhibition of carcinoma cell adhesion using various chemotherapeutic agents plays an important role in cancer treatment (Efferth et al., 2001; Huang et al., 2007; Buommino et al., 2009).

The results from the current study demonstrated that ludartin treatment significantly inhibits the adhesive potential of OVCAR5 ovarian cancer cells. Ludartin also exhibited inhibitory effect on the proliferation rate of OVCAR5 ovarian cancer cells. Adhesion of the carcinoma cells is followed by invasion and migration and these properties make the tumor aggressive (Cattaruzza and Perris, 2005). Results from the present study demonstrated that ludartin treatment significantly inhibits invasion and migration potential of the OVCAR5 ovarian cancer cells.
It is reported that ovarian cancer cells metastasize to the other tissues including, liver, lungs, pancreas etc (Disbrow et al., 2005; Zhou et al., 2010; Wang et al., 2010). Current study showed that in the rats transplanted with orthotopic ovarian cancer, ludartin treatment inhibited metastasis of ovarian cancer cells to lungs. Metastasis of ovarian cancer cells to intestinal tissues was also inhibited by ludartin. The process of carcinoma cell migration and invasion is facilitated by the involvement of various factors including, phosphorylated focal adhesion kinase (pFAK), MMPs, etc. (Hoekstra et al., 2001; Parsons et al., 2000). The results from the current study demonstrated that ludartin treatment inhibits the expression of $\mathrm{pFAK}$ in the ovarian cancer cells. Studies have revealed that metalloproteins like MMP-9 play vital role in promoting the aggressive behavior of cancers (Hoekstra et al., 2001). In the present study the expression of MMP -9 was also reduced by ludartin treatment in ovarian cancer cells. Tumor cells metastasize to various surrounding organs like lungs, liver resulting the development of tumor in those organs as well (Jonjic et al., 1992; Wang et al., 2005). In the present study, ludartin treatment prevented the spread of tumor cells to lungs and intestinal tissues in the rats with orthotopic tumors.

\section{Conclusion}

Ludartin treatment inhibits the proliferation, invasion and migration of ovarian cancer cells through downregulation of pFAK and MMPs. Thus, ludartin can be used for the treatment ovarian cancer.

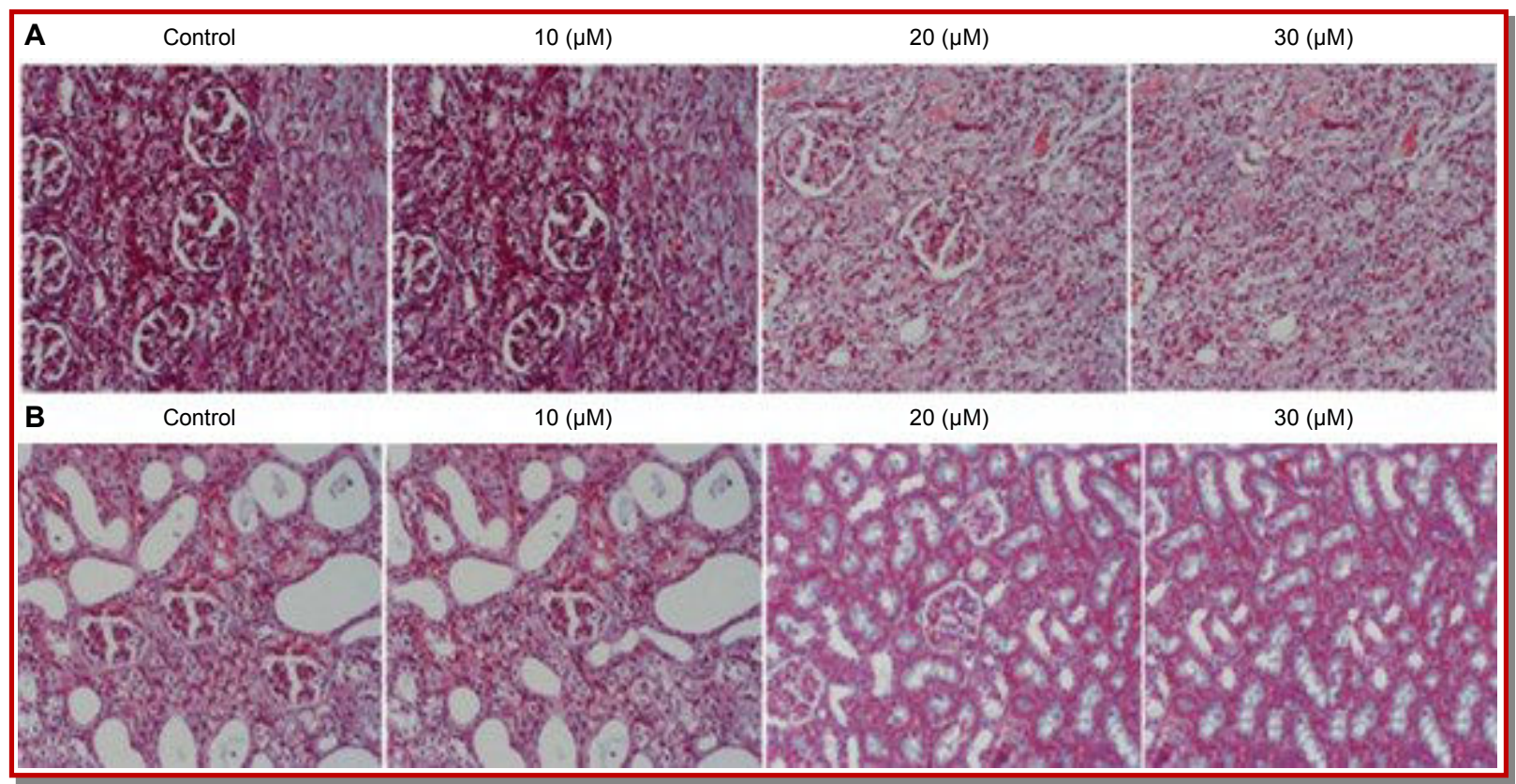

Figure 5: Histopathological examination of lung and intestinal tissues of rats bearing orthotopictumours following ludartin treatment. The rats in the treatment group were given $30 \mu \mathrm{M} / \mathrm{kg}$ doses of ludartin for 15 days daily. The lung and intestinal tissues were stained using HE staining and then subjected to histopathological examination 


\section{Ethical Issue}

The animal experimental procedures were performed according to the guidelines for ethical conduct in the care and use of experimental animals of the Hubei University of Medicine Wuhan, Hubei, China). The study was approved by the ethics committee of the Hubei University of Medicine Wuhan, Hubei, China).

\section{Conflict of Interest}

The authors declare no conflict of interest in publishing these results.

\section{References}

Berridge MV, Tan AS, Herst PM. Tetrazolium dyes as tools in cell biology: New insights into their cellular reduction. Biotechnol Ann Rev. 2005; 11: 127-52.

Bertone-Johnson ER. Epidemiology of ovarian cancer: A status report. Lancet 2005; 365: 101-02.

Blanco JG, Gil RR, Alvarez CI, Patrito LC, Genti Raimondi S, Flury A. A novel activity for a group of sesquiterpene lactones: Inhibition of aromatase. FEBS Lett. 1997; 409: 396400.

Buommino E, Baroni A, Canozo N, et al. Artemisinin reduces human melanoma cell migration by down-regulating alpha $\mathrm{V}$ beta 3 integrin and reducing metalloproteinase 2 production. Invest New Drugs. 2009; 27: 412-18.

Cattaruzza S, Perris R. Proteoglycan control of cell movement during wound healing and cancer spreading. Matrix Biol. 2005; 24: 400-17.

Disbrow GL, Baege AC, Kierpiec KA, et al. Dihydroartemisinin is cytotoxic to papillomavirus-expressing epithelial cells in vitro and in vivo. Cancer Res. 2005; 65: 10854-61.

Efferth T, Dunstan H, Sauerbrey A, Miyachi H, Chitambar CR. The anti-malarial artesunate is also active against cancer. Int J Oncol. 2001; 18: 767-73.
Hoekstra R, Eskens FA, Verweij J. Matrix metalloproteinase inhibitors: Current developments and future perspectives. Oncologist 2001; 6: 415-27.

Huang XJ, Ma ZQ, Zhang WP, Lu YB, Wei EQ. Dihydroartemisinin exerts cytotoxic effects and inhibits hypoxia inducible factor-1 alpha activation in C6 glioma cells. J Pharm Pharmacol. 2007; 59: 849-56.

Jonjic N, Peri G, Bernasconi S, et al. Expression of adhesion molecules and chemotactic cytokines in cultured human mesothelial cells. J Exp Med. 1992; 176: 1165-74.

Muftuoglu Y, Mustata Y. Pharmacophore modeling strategies for the development of novel nonsteroidal inhibitors of human aromatase (CYP19). Bioorg Med Chem Lett. 2010; 20: 3050-64.

Parsons JT, Martin KH, Slack JK, Taylor JM, Weed SA. Focal adhesion kinase: A regulator of focal adhesion dynamics and cell movement. Oncogene 2000; 19: 5606-13.

Rahman MA, Hussain A. Anticancer activity and apoptosis inducing effect of methanolic extract of Cordia dichotoma against human cancer cell line. Bangladesh J Pharmacol. 2015; 10: 27-34

Raki M, Rein DT, Kanerva A, Hemminki A. Gene transfer approaches for gynecological diseases. Mol Ther. 2006; 14: 154-63.

Wang SJ, Gao Y, Chen H, et al. Dihydroartemisinin inactivates NF-kappaB and potentiates the anti-tumor effect of gemcitabine on pancreatic cancer both in vitro and in vivo. Cancer Lett. 2010; 293: 99-108.

Wang E, Ngalame Y, Panelli MC, et al. Peritoneal and subperitoneal stroma may facilitate regional spread of ovarian cancer. Clin Cancer Res. 2005; 11: 113-22.

Zhang J, Wang B. Arsenic trioxide $\left(\mathrm{As}_{2} \mathrm{O}_{3}\right)$ inhibits peritoneal invasion of ovarian carcinoma cells in vitro and in vivo. Gynecol Oncol. 2006; 103: 199-206.

Zhou HJ, Zhang JL, Li A, Wang Z, Lou XE. Dihydroartemisinin improves the efficiency of chemotherapeutics in lung carcinomas in vivo and inhibits murine Lewis lung carcinoma cell line growth in vitro. Cancer Chemother Pharmacol. 2010; 66: 21-29.

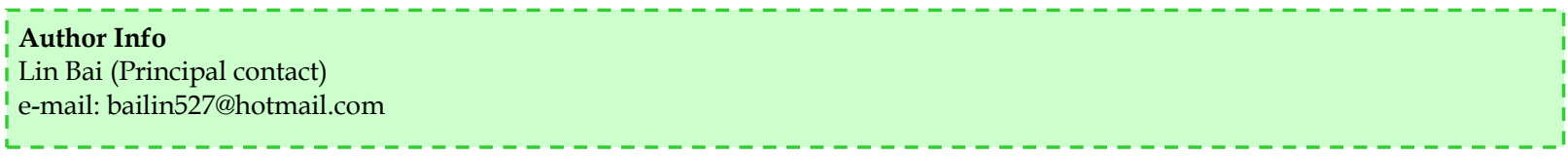




\section{Your feedback about this paper}

1. Number of times you have read this paper 0

2. Number of times you have seen the video clip 0

3. Quality of paper Click

4. Your comments

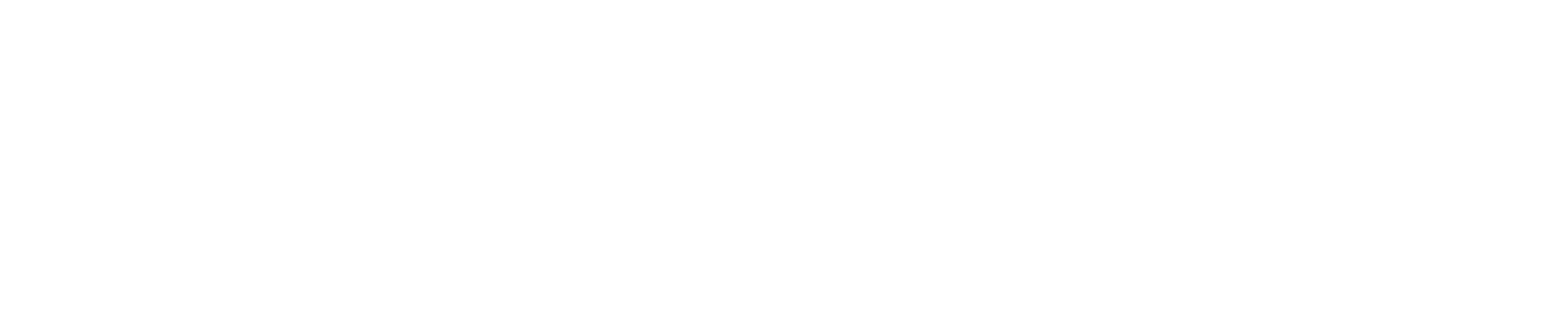

